Preprint submitted to Springer

\title{
Authors:
}

Natalia Vizcaíno-Palomar*, Lorena Gómez-Aparicio, Javier Pavón-García, Carmen

Bartolomé-Esteban, Julio Álvarez-Jiménez, Miguel A. Zavala

Full title: Main biotic drivers of tree growth in a developing Juniperus thurifera stand in Central Spain

Running title: Tree growth patterns in reproductive and non-reproductive individuals of Juniperus thurifera in Central Spain 


\section{Affiliation and addresses}

Natalia Vizcaíno Palomar,

Department of Forest Ecology and Genetics, Forest Research Centre (INIA). Ctra. de A Coruña km 7.5, 28040 Madrid, Spain.

Forest Ecology and Restoration Group, Department of Life Sciences, Science Building, University of Alcalá, ES-28871, Alcalá de Henares (Madrid), Spain.

Phone: (+34) 913473904; Fax: (+34) 913572293. natalia.vizcaino.palomar@gmail.com *corresponding author

Dra. Lorena Gómez Aparicio,

Instituto de Recursos Naturales y Agrobiología de Sevilla (IRNAS), CSIC, PO Box 1052, Sevilla E-41080, Spain. lorenag@irnase.csic.es

Dr. Javier Pavón García,

Forest Ecology and Restoration Group, Department of Life Sciences, Science Building, University of Alcalá, Campus Universitario, 28871, Alcalá de Henares (Madrid), Spain. javierpavongarcia@gmail.com

Dra. Carmen Bartolomé Esteban

Forest Ecology and Restoration Group, Department of Life Sciences, Science Building, University of Alcalá, Campus Universitario, 28871, Alcalá de Henares (Madrid), Spain. carmen.bartolome@uah.es

Dr. Julio Álvarez Jiménez, 


\section{Preprint submitted to Springer}

Forest Ecology and Restoration Group, Department of Life Sciences, Science Building, University of Alcalá, Campus Universitario, 28871, Alcalá de Henares (Madrid), Spain. julioaj@uah.es

Dr. Miguel A. Zavala,

Forest Ecology and Restoration Group, Department of Life Sciences, Science Building, University of Alcalá, Campus Universitario, 28871, Alcalá de Henares (Madrid), Spain. madezavala@gmail.com 


\section{Abstract}

Over the last few decades, abandonment of traditional management practices in Spain has led to widespread stand densification and has favoured the expansion of some forest species that previously exhibited more restricted ranges. Spanish juniper (Juniperus thurifera L.) woodlands are experiencing this phenomenon due to agricultural land abandonment and a decrease in the livestock pressure. Yet the main drivers underlying stand structure and dynamics at this novel scenario are poorly understood. In this study, we investigate the main biotic drivers of tree growth in a high-density stand of the dioecious $J$. thurifera at an early developmental stage (mean tree age of 32 years, 50 years after land abandonment). Tree growth was measured by coring 299 individuals of different reproductive classes (male, female and non-reproductive). Neighbourhood models were used to assess the relative importance of tree size and neighbourhood competition on tree growth of each reproductive class in the study plot. We found that tree size had the strongest effect on tree growth, whereas the effect of intraspecific competition was negligible. We observed differences in growth patterns among reproductive classes along trunk diameter sizes. Thus, at smaller sizes the three reproductive classes presented identical patterns of growth. However, at bigger sizes, females were the fastest growing individuals, followed by males and nonreproductive individuals. Overall, our results suggest that in young $J$. thurifera monospecific forests, where self-thinning processes may have not undergone yet, tree size and the reproductive class could play a relatively more important role than competition as drivers of tree growth. These findings constitute new information which contributes to understanding growth dynamics at early developmental stages in this dioecious species. Furthermore, our results provide guidelines for silvicultural managing; suggesting that at these young juniper stands thinning would likely not translate into enhanced growth on remnant trees. 
Preprint submitted to Springer

Keywords: dioecious, intraspecific competition, land use abandonment, Mediterranean forests, neighbourhood models, reproductive class, tree growth 


\section{Introduction}

In Mediterranean countries human activities have shaped the structure and function of the forest ecosystem for ages (e.g. Thirgood 1981; Blondel and Aronson 1995; Urbieta et al. 2008). Over the last few decades, abandonment of traditional management practices has led to a general stand densification and has favoured forest expansion (Matesanz et al. 2009; Olano et al. 2011; Vayreda et al. 2012). These relative novel conditions mostly appear confined either to unproductive marginal lands or to mountain areas, where abandonment of traditional agriculture and the decrease in livestock pressure have happened as a consequence of depopulation of rural areas (Thompson, 2005). Several studies have reported forest expansion and densification in different tree species (Poyatos et al. 2003; Gehrig-Fasel et al. 2007). For example, Améztegui et al. (2010) reported that Pinus uncinata, a mountain pine species, has increased its surface coverage in the Catalan Pyrenees (north-east Spain) by more than $16 \%$ in a period of 50 years.

Likewise, Spanish juniper (Juniperus thurifera L.) woodlands are experiencing a similar phenomenon (Blanco et al. 2005; Olano et al. 2011; Gimeno et al. 2012c). They are one of the dominant plant communities in the scarcely-populated mountain regions of the central Iberian Peninsula. In the past, juniper woodlands were largely shaped by livestock grazing and wood extraction pressures by the inhabitants of the area. As a consequence, recruitment, survival and growth rates of the species were arrested (De Soto et al. 2010, Olano et al. 2008). However, nowadays a process of densification is described due to the decline of these traditional activities. As a result of these novel conditions, these forests may undergo very different stand dynamics in relation to past forest dynamics.

Over the last decade several studies have focused on understanding the patterns of juniper growth in Spanish woodlands either as a consequence of land use changes (Olano et 


\section{Preprint submitted to Springer}

al. 2008b; DeSoto et al. 2010; Olano et al. 2011) or as a gender-specific response (e.g. Montesinos et al. 2006; Rozas et al. 2009; Montesinos et al. 2012; Gimeno et al. 2012a). Nevertheless, most of these studies have been conducted in mature stands, where average individual age was 70-100 years (e.g. Rozas et al. 2008; Olano et al. 2008; DeSoto et al. 2010, but see Gimeno et al. 2012ac). In contrast, the mechanisms driving population dynamics at earlier stages (age $\sim 40$ years), which are representative of these new juniper forests, have hardly been explored. In particular, we aimed to understand the role of intraspecific and intersexual competition in these new stands resulting from the release of traditional practices. Overall, this information could be crucial for establishing new scientific based management options for the future in this species.

Population structure results from a combination of abiotic and biotic factors, ranging from environmental conditions to inter- and intra-specific interactions (e.g. Hara 1984; Stoll et al. 1994; Coomes and Allen 2007). We hypothesize that three potentially important biotic factors might explain inter-individual differences in tree growth in high-density novel stands: (i) the reproductive class of the individual tree, (ii) tree size and (iii) neighbourhood competition. According to allocation theory (Chapin III et al. 1987) resources acquired by individual plants must be distributed among several competing functions, chiefly growth, maintenance and reproduction (Harper 1967). Consequently, the growth of non-reproductive individuals might be expected to differ from that of reproductive ones (Delph 1999). Specifically, we expect that non-reproductive individuals might invest a null amount of resources in reproduction, and hence show greater growth rates than reproductive individuals (Bazzaz et al. 1997). Moreover, in dioecious plant species, male and female individuals are expected to differ in their vegetative and reproductive strategies leading to differences in population structure and dynamics (Freeman et al. 1976). In general, males 


\section{Preprint submitted to Springer}

91 show relatively higher vegetative growth (Lloyd and Webb 1977; Cipollini and Whigham 1994 but see Gimeno et al. 2012a) and survival rates than females (Doust et al. 1987; Allen and Antons 1993).

Size is one of the main determinants of a plant's interaction with its environment (Schulze 1982) and a common factor used to predict tree growth (Coomes and Allen 2007; Gómez-Aparicio et al. 2011). The relationship between size and growth rate arise both from internal and physiological causes (Gower et al. 1996), and because increasing size affects a tree's ability to acquire resources. The most common pattern for this relationship is a rapid increase of growth at small tree sizes until a maximum growth is reached at some intermediate size, and then a more or less sharp decline (depending on the species) in growth in larger size classes (Muller-Landau et al. 2006; Russo et al. 2007; Gómez-Aparicio et al. 2011). Finally, competition at early stages of forest stand development constitutes a third critical factor influencing individual tree growth and determining future stand development patterns (Coomes and Allen 2007; Harper 1977; Kobe 1996). Furthermore, intra-specific competition is usually stronger than inter-specific competition (Tilman 1982; Stoll and Newbery 2005). This may be due to a higher competitive equivalence among individuals of the same species than among individuals of different species (Silvertown and Charlesworth 2001). Within species, differences in resource allocation between reproductive classes might turn into dissimilarities in the competitive ability of males, females and non-reproductive individuals. Specifically we expect females to compete less strongly than males and nonreproductive individuals.

In this study, we aimed to explore tree growth patterns of the dioecious species Juniperus thurifera L. in a forest stand which is representative of new juniper forests resulting from agricultural and livestock farming abandonment (i.e. c.f 50 years) in the 


\section{Preprint submitted to Springer}

115 Iberian Peninsula. We used neighborhood models to predict tree growth for different 116 reproductive classes (males, females and non-reproductive) as a function of size and

117 intraspecific competition from neighbours (including interactions within and among the 118 different reproductive classes). We specifically addressed the following hypotheses: (i) in a 119 high density forest stand and at early stages of development, tree size is expected to be an 120 important factor determining tree growth, (ii) intraspecific competition is expected to have a 121 negative effect on tree growth, (iii) tree growth rates are expected to differ among different 122 reproductive classes. Specifically, non-reproductive individuals are expected to grow faster 123 than males and these in turn faster than females. 


\section{Preprint submitted to Springer}

\section{Material and methods}

Study species and study area

Juniperus thurifera L. (Cupressaceae) is mainly a dioecious tree, though infrequently monoecious trees are found (Borel and Polidori, 1983, Lathuillière, 1994). In the Iberian Peninsula this species is mainly found in high plateaus and mountain regions of the centraleast at a variety of altitudes (140-1,800 m a.s.l) in continental and cold Mediterranean climatic conditions (Gauquellin et al. 1999, Terrab et al. 2008, Fig. S1). It is usually the dominant species in low-density woodlands on poor, shallow, rocky soils (both acidic and calcareous, although more abundant in the latter) (Gauquelin et al. 1999). Juniper males and females flower at the end of the winter and wind-pollinated female cones mature during 20 months. It is a masting species, that is, individuals present low or null reproduction for several years but every few years most individuals in a population present a massive reproduction event (Montesinos, 2007). It can also be considered a slow-growing species (Gómez-Aparicio et al. 2011).

The study area was located in Monte Pradenilla (Segovia, north-central Spain), near the Sierra of Guadarrama, at 1,120 m a.s.l. Soils are calcareous cambisols developed on Cretaceous dolomitic substrates. Climate in this region is continental Mediterranean, with hot and dry summers and cold and long winters. Mean annual rainfall is $572.41 \mathrm{~mm}$ (1957-

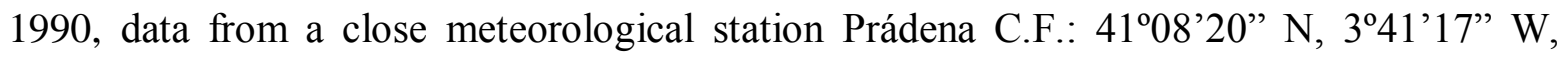
1,110 m a.s.1.). Mean annual temperature, mean minimum temperature and mean maximum temperature are $10.6{ }^{\circ} \mathrm{C}, 4.3{ }^{\circ} \mathrm{C}$ and $16.83{ }^{\circ} \mathrm{C}$, respectively (1988-1992; all data provided by the Spanish Agencia Estatal de Meteorología). The study area was dominated by the species J. thurifera L., which forms even-aged monospecific forests with scatter presence of Juniperus communis L. subsp. hemisphaerica (K. Presl.) and a sparse understory of small 


\section{Preprint submitted to Springer}

calcicolous shrubs. Traditional management (livestock grazing and wood harvest) was abandoned in the late 70s; the stand is currently in an early development stage. Within this study area we selected a rectangular study plot of approximately $2,250 \mathrm{~m}^{2}$, with a high density of trees $\left(0.71\right.$ trees $\left.\mathrm{m}^{-2}\right)$, fairly flat topography and homogenous in rockiness ( $\mathrm{J}$. Pavón-García, personal observation).

\section{Data collection and reproductive class identification}

Data collection was conducted during the summer and fall of 1993 . We selected this time of the year because it was adequate to visually identify the reproductive structures of individuals (when existing). We tagged all the individuals presented in the study plot, a total of 1604. The study plot was composed of 447 reproductive individuals (225 males, 215 females and 7 monoecious individuals) and 1,157 non-reproductive individuals. Within reproductive individuals (males and females), $17 \%$ presented multi-caulis structure, i.e. more than one stem. Within the non-reproductive class, $19 \%$ presented multicaulis structure. In the study plot, the reproductive: non-reproductive ratio was $0.39: 1$ and the sex ratio (male: female) was 1.05: 1. For each individual in the study plot, we recorded tree size by measuring the trunk perimeter at $10 \mathrm{~cm}$ from the ground, total height and the reproductive class (males, females and non-reproductive). Reproductive class assignation was based on the presence of reproductive structures. Accordingly to this criterion, the male class was composed of individuals with male cones; the female class was composed of individuals with either female cones or the existence of fruits; and the non-reproductive class was composed of those individuals without any reproductive structure in their branches yet. Reproductive class assignation was verified two more times, in 1994 and 1998. This 


\section{Preprint submitted to Springer}

verification helped us to assure that non-reproductive individuals were not a consequence of a non-masting year.

Wood cores were taken from a subsample of the individuals in each reproductive class (hereafter target trees) for characterization of growth rates and tree age. Target trees were selected following three main criteria (Pavón-García 2005): (i) trees should have a unique trunk in order to facilitate growth rate estimates, (ii) trees should have a minimum diameter of $25 \mathrm{~mm}$ (measured at $10 \mathrm{~cm}$ from the ground) in order to be able to core the trunk and to minimize serious damage after coring, and (iii) overlapping among neighbourhood areas should be avoided or minimized as much as possible. Overall, 115 males, 105 females and 79 non-reproductive individuals were selected (Table 1, Fig. 1). Wood cores were taken as close as possible to the ground, at approximately $10 \mathrm{~cm}$, perpendicularly to the trunk and heading north east and reaching central trunk section by using a Pressler's increment borer. Cores were mechanically surfaced and then manually polished with a series of successively finer grades of sandpaper until the xylem cellular structure was clearly visible. In order to correctly visualize tree rings, a dissolvent (toluene) was added to remove traces or wood resins. Tree rings were visually dated following a standard procedure (Stokes and Smiley, 1968) using a binocular regulated glass which helps to measure and count the tree rings. The double rings were scarce and easily detected. Radial growth of each target tree $\left(\mathrm{mm} \mathrm{yr}^{-1}\right)$ was calculated by dividing the total length of the last ten tree-ring growth $(\mathrm{mm})$ by the number of 10 years. Finally, we characterized the neighborhood of each target tree by recording the number, size and reproductive class of each neighbour tree within three different radii $\left(\mathrm{R}_{\mathrm{i}}: 1 \mathrm{~m}, 2 \mathrm{~m}, 3 \mathrm{~m}\right)$ from the target tree (Table 2$)$.

\section{Statistical analysis of growth models}




\section{Preprint submitted to Springer}

196

197

198

199

200

201

202

203

204

205

206

207

208

209

210

211

212

213

214

215

216

217

We used a neighbourhood approach based on similar studies of tree growth (Canham and Uriarte 2006; Gómez-Aparicio and Canham 2008) to predict recent tree growth (last ten years) of the 299 target trees. Growth data were grouped in four subsets: one including all individuals (i.e. without differentiation regarding the reproductive class); a second one including only male individuals; a third one including only female individuals; and the fourth one including only non-reproductive individuals. We predicted radial tree growth in

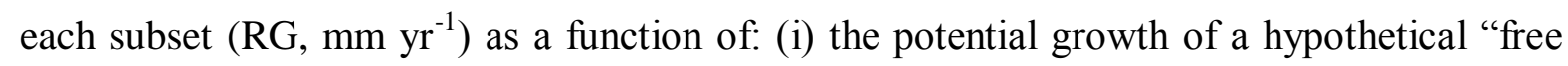

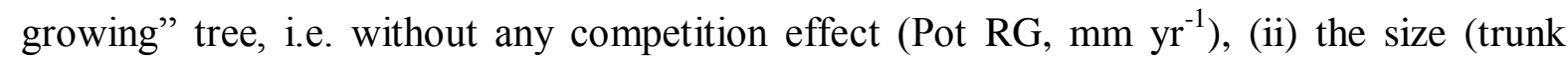
diameter) of the target tree and (iii) competition from neighbouring trees. The model takes the form:

$$
\mathrm{RG}=\text { Pot } \mathrm{RG} \times \mathrm{x} \text { Size effect } \times \text { Competition effect } \quad \text { eqn } 1
$$

where Pot RG is the parameter estimated from the data. The size and competition effects are scalars ranging from 0 to 1 , which act to reduce potential growth of a hypothetical "free growing" tree. In this model, at a Competition effect of 0 (intense competition), growth is 0 , and at a Competition effect of 1 , growth is no longer limited by this interaction. Similarly to other studies (Canham et al. 2006; Coates et al. 2009, Gómez-Aparicio et al. 2011) we used a lognormal function to shape the size effect (eqn 2).

$$
\text { Size effect }=\exp \left[-\frac{1}{2}\left(\frac{\ln \left(D / X_{0}\right)}{X_{b}}\right)^{2}\right]
$$

eqn 2

where $\mathrm{D}$ is the trunk diameter $(\mathrm{mm})$ of the target tree, $\mathrm{X}_{0}$ is a parameter that represents the trunk diameter $(\mathrm{mm})$ of the target tree at which Pot RG occurs (i.e., the peak of the lognormal shape), and $\mathrm{X}_{\mathrm{b}}$ is a parameter that determines the breadth of the function. The lognormal function is flexible enough to be monotonically increasing (i.e., when $\mathrm{X}_{0}$ is very 


\section{Preprint submitted to Springer}

218

219

220

221

222

224

225

226

227

230

231

232

233

234

235

236

237

238

239

large), decreasing (i.e., when $\mathrm{X}_{0}$ is very small), or to have a single "hump" and a skew to the left when $\mathrm{X}_{0}$ is within the normal range of trunk diameter.

The competition effect was modelled using a Neighbourhood Competition Index (NCI). This index takes into account the total basal area from neighbours contained in circumferences at different distances from the target tree. This type of indices has been shown to be generally sufficient to predict competition effects in relatively uniform evenaged stands (Lorimer 1983). Neighbours were defined as individuals growing within three different radii $\left(\mathrm{R}_{\mathrm{i}}: 1\right.$ m, 2 m, 3 m) from target trees (Weiner 1984; Silander and Pacala 1985) within the study plot. We tried three different radii because the effects of local crowding can potentially vary depending on the radius used to define the local neighbourhood (Peterson and Squiers 1995; He and Duncan 2000). The NCI took the form:

$$
\mathrm{NCI}_{\mathrm{Ri}}=\sum_{j=0}^{n} B A_{j}
$$

eqn3

where $\mathrm{BA}_{\mathrm{j}}$ is the basal area of the neighbour trees $\left(\mathrm{cm}^{2}\right)$ within one of the three influence areas tested, and $\mathrm{R}_{\mathrm{i}}$ is the distance to the target tree (either $1 \mathrm{~m}, 2 \mathrm{~m}$ or $3 \mathrm{~m}$ ).

We tested two forms of the NCI: (i) all neighbours were considered to be equivalent (eqn. 3), and (ii) the effect of neighbours was a function of their reproductive class (male, female and non-reproductive). The reproductive condition of the neighbour was included into the NCI by a new parameter $\left(\lambda_{\mathrm{k}}\right)$ that ranges from 0 to 1 and allows for differences among sexual condition in their competitive effect on the target tree (eqn4):

$$
\mathrm{NCI}_{\mathrm{Ri}}=\sum_{i=0}^{n} \lambda_{k} \times B A_{j}
$$

eqn4

The competition effect was assumed to decrease exponentially as a function of the NCI: 
where $\alpha$ and $\mathrm{C}$ are parameters estimated by the analyses that determine the shape of the neighbour effect on NCI and the intensity of competition, respectively.

We also tested whether the sensitivity of the target tree to competition decreased or increased with tree size. This allowed us to test whether a given level of competition had a greater effect depending on the size of the target trees (Gómez-Aparicio et al. 2008). To this end, the exponential decay term $(\mathrm{C}$, eqn5) was allowed to vary as a function of target tree size, following the functional form:

If $\gamma=0$, then sensitivity to competition does not vary as a function of target tree size. If $\gamma<$

0 , then sensitivity to competition declines as target tree trunk diameter increases, and if $\gamma>0$ then larger trees are more sensitive to a given level of crowding than smaller trees.

Parameter estimation and comparison of alternate models

The modelling process followed two steps. First, we ran univariate models for each effect (size and competition) independently, and compared them to the null model which assumes constant growth in the stand. By doing this, we assessed whether including any of these effects into a model significantly improved its explanatory power. Second, bivariate models were fitted when both size and competition were found to have an effect on growth when evaluated alone. The models were done separately for each of the four subsets of data (i.e., all target individuals, males, females and non-reproductive individuals). likely parameters (i.e. the parameters that maximize the log-likelihood) given our observed data (Goffe et al. 1994). We used information criteria as an indicator of parsimony and 


\section{Preprint submitted to Springer}

264 likelihood (the Akaike Information Criterion corrected for small sample sizes, AIC c $_{\text {) }}$ to select the best growth model (Burnham and Anderson 2002). The absolute magnitude of the differences in AIC between alternate models ( $\triangle \mathrm{AIC}$ ) provides an objective measure of the strength of empirical support for the competing models. The model with the strongest empirical support has the minimum AIC (Akaike 1992). Models with $\triangle \mathrm{AIC}$ between 0 and 2 were considered to have equivalent and substantial empirical support, $\Delta \mathrm{AIC}$ between 4 and 7 indicated less support, and models with $\triangle \mathrm{AIC}>10$ were dismissed, as they had negligible empirical support (Burnham and Anderson 2002). As a measure of goodness-of-fit we used the $\mathrm{R}^{2}$ of the regression (1 - SSE/SST, SSE: sum of squares error, SST: sum of squares total) and as a measure of bias we used the slope of the regression with a zero intercept between observed and predicted radial growth (with an unbiased model having a slope of 1). We used asymptotic two-unit support intervals to assess the strength of evidence for individual maximum likelihood parameter estimates (Edwards 1992), which is roughly equivalent to a 95\% support limit defined using a likelihood ratio test (Hilborn and Mangel, 1997). A support interval is defined as the range of the parameter value that results in less than a twounit difference in AIC. Residuals were normally distributed $\mathrm{N} \sim(0,1)$. All the analyses were done in the $\mathrm{R}$ environment ( $\mathrm{R}$ Development Core Team 2013) using the likelihood package version 1.5 (Murphy, 2012). 


\section{Preprint submitted to Springer}

283

284

285

286

287

\section{Results}

\section{Biotic factors of tree growth assessed by model comparison and evaluation}

All of the best models produced unbiased estimates of growth (i.e. slopes of predicted versus observed growth were all very close to 1) and the percentage of variance explained by the best models ranged from $35 \%$ to $49 \%$ (Table 3, Fig. S2). On one hand, models that included the effect of target tree size on growth had in all cases a better fit to the data than the null model (Table 3). On the other hand, models that included the effect of competition on tree growth had larger support than the null model (i.e., lower $\mathrm{AIC}_{\mathrm{c}}$ ) for all the trees together at $\mathrm{R}$ $=2 \mathrm{~m}$ and for female target trees at all the radii, but not for male or non-reproductive trees. However, bivariate models including size and competition were never a better fit to the data that univariate models considering only size (Table 3).

\section{Differential growth patterns between reproductive classes}

The three reproductive classes showed different patterns of variation in predicted radial growth as a function of target tree size (Fig. 2). At small sizes predicted radial growth of the three reproductive classes was similar and increased rapidly with trunk diameter. However, at a certain size non-reproductive individuals grew much more slowly than non-reproductive individuals. Non-reproductive individuals reached a growth peak at an intermediate size of trunk diameter and a slight decline afterwards. In contrast, reproductive individuals kept a monotonic growth curve, with female individuals of large size growing faster than males (Fig. 2).

Differences in growth rates among reproductive classes were also supported by the different values of the potential radial growth parameter (Pot RG), which measures the growth rate of a hypothetical "free growing tree" of optimal size (i.e. a target tree with D = 


\section{Preprint submitted to Springer}

$307 \mathrm{X}_{0}$, eqn 1). Predicted potential growth rates (Pot RG) were highest in females (2.56 [2.39-

308 2.73] $\mathrm{mm} \mathrm{yr}^{-1}$, mean [support interval]), followed by males (1.93 [1.83-2.03] $\left.\mathrm{mm} \mathrm{yr}^{-1} 1\right)$ and 309 non-reproductive individuals (0.99 [0.94-1.00] $\left.\mathrm{mm} \mathrm{yr}^{-1}\right)$ (Table 4). 


\section{Preprint submitted to Springer}

\section{Discussion}

\section{Biotic factors influencing tree growth patterns}

313 Our results showed that Juniperus growth at early stages of stand development was largely

314 governed by tree size and the reproductive class rather than by neighbourhood competition.

315 Specifically, in agreement with our first hypothesis, size of the target tree was the main 316 factor driving tree growth (e.g. Gimeno et al. 2012a; Lee et al. 2003; Mencuccini et al. 317 2007). The size-growth curve showed a rapid increase of growth with size for the three 318 reproductive classes (see also Gómez-Aparicio et al. 2011 for a similar result). However, the 319 shape of the curves indicated that non-reproductive individuals have a lower growth 320 potential than reproductive individuals, reaching a growth peak much faster than reproductive individuals. In fact, the shape of the size-growth curve for reproductive individuals suggests that such a peak would occur at larger sizes than those found in our study site. A plausible explanation for this would be the fact that our study forest is relatively young and the trees are relatively small, so our study population might not include reproductive individuals large enough to have reached their maximum growth yet.

Intraspecific competition did not constrain tree growth, neither when all neighbours were considered as equal competitors nor when they were separated into different reproductive classes. This result is contrary to our second hypothesis, which stated that neighbourhood competition may become a key driver of individual tree growth as previously reported for Juniperus thurifera (Gimeno et al. 2012c) and other dioecious tree species

331 (Herrera 1988; Vasiliuskas and Aarssen 1992; Houle and Duchesne 1999; Zhang et al. 2009). These studies have addressed the existence of intraspecific competition, and moreover, they have described inter- and intra-specific interaction between reproductive classes, although without finding consistent trends. For example, Vasiliuskas et al. (1992) 


\section{Preprint submitted to Springer}

showed for Juniperus virginiana (Cupressaceae) that the presence of neighbours decreased tree growth, independently of the reproductive class of the nearest neighbours. Meanwhile, Houle and Duchesne (1999) in J. communis suggested the existence of a moderate intraspecific competition only between males. These studies, however, focused on uneven aged populations that might already be experiencing self-thinning processes which could explain the existence of the observed competition interactions. On the contrary, in our young forest of study, the lack of canopy overlapping among young Juniperus (J. Pavón-García, personal observation), and the inherent slow-growing resource-conservative strategy of the species (García-Morote et al. 2012; Gómez-Aparicio et al. 2011) would help to explain the lack of competitive interactions among Juniperus individuals despite the high stand density.

\section{Differential growth rates between reproductive classes}

Our results suggested that females may grow faster than males. This finding is confirmed by both the size-growth curves and the potential growth rates (a) estimated in the models. This result is in disagreement with our third hypothesis based on the fact that differences in resource investments to reproduction could result in different patterns of growth, with females showing slower growth rates than males and non-reproductive individuals (Herrera 1988; Vasiliuskas and Aarssen 1992; Allen and Antons 1993). Previous studies with $J$. thurifera suggest the lack of a consensus about which gender grows faster than the other and why. For example, higher growth rates in males have been interpreted as the delayed cost of reproduction in females (Gauquelin et al. 2002; Montesinos et al. 2006). However, other studies have found no differences in growth rates between males and females of Juniperus thurifera (Gimeno et al. 2012a; Gimeno et al. 2012d), even in situations where the female reproductive effort was much greater than that of males (Ortiz 2002). Finally, some authors 


\section{Preprint submitted to Springer}

359

360

361

362

363

364

365

366

367

368

369

370

371

372

373

374

375

376

377

378

379

380

381

have found females to grow faster than males in individuals larger than those from our study plot (Rozas et al. 2009). Our results are in agreement with this last line of evidence. A higher female growth rate might be explained by the underlying mechanisms which offset female reproduction costs, e.g. photosynthetic reproductive structures, delayed reproduction, nutrient resorption from senescing organs or fallen fruits under the female's canopy, module specialization or higher photosynthetic rates in females (Delph 1990, Delph 1999; Obeso 2002). In particular, Montesinos et al. (2012) suggested that female $J$. thurifera seem to have a long-term strategy which allows them to store and use their resources for future requirements, whilst males seem to have a short-term strategy which makes them adjust their growth and reproduction as a function of the current resource availability.

Lastly, and also contrary to our third hypothesis, our results showed that nonreproductive individuals had lower growth rates than male and female individuals. Our expectation was based on the idea that a lack of reproduction costs incurred by nonreproductive individuals would result in greater growth rates than reproductive individuals, as found in previous studies for the same species (Gimeno et al. 2012d). A plausible explanation to this finding could be related to the potential existence of small-scale spatial heterogeneity in environmental conditions (e.g. soil fertility), with non-reproductive individuals being located in sub-optimal microsites that could limit their capacity to invest in both growth and reproduction. In fact, mean size of non-reproductive individuals was smaller than that of reproductive individuals despite having similar ages. Moreover, small junipers present higher sensitivity than large ones to stressful environmental conditions (Rozas et al. 2009), which might further limit their performance (i.e. lower growth rates and delayed reproduction). However, we cannot discard other alternative causes, such as the 


\section{Preprint submitted to Springer}

382

383

384

385

386

387

388

389

390

391

392

393

394

395

396

397

398

399

400

401

402

403

404

existence of genetic variability or seed size effects, that might have prevented nonreproductive individuals from having a better performance,

Overall, our results suggest that in young $J$. thurifera monospecific forests, where self-thinning processes may have not undergone yet, tree size and the reproductive class could play a relatively more important role than competition as drivers of tree growth and stand dynamics. Female Juniperus apparently make a much more efficient use of their available resources allowing them to grow faster than males and non-reproductive individuals. The non-reproductive condition of individuals could be linked to specific microsite conditions or genetic variability effects which could hamper their development. Although competition is considered a major determinant of tree performance and population dynamics (Weiner 1984), intraspecific differences in growth patterns alone can also be of paramount importance in explaining population structure and dynamics (e.g. Zavala et al. 2007).

In conclusion, this study contributes to understanding growth dynamics at early developmental stages in a dioecious tree species such as Juniperus thurifera. Additionally, our study provides guidelines to develop silvicultural recommendations in order to manage these new woodlands. Recently, juniper wood has aroused interest due to its quality for constructions (Crespo et al. 2006). Therefore, managers aim to seek both quantity and quality wood by controlling stand density throughout thinning (Nyland, 1996). Our results suggest that at this early successional stage, thinning would have little influence on the growth of remnant trees, as competition did not seem to limit growth of relatively young junipers. 


\section{Preprint submitted to Springer}

405

406

407

408

409

410

411

412

413

414 Conflict of interest: None declared. 


\section{Preprint submitted to Springer}

417

418

419

420

421

422

423

424

425

426

427

428

429

430

431

432

433

434

435

436

437

438

439

440

441

442

443

444

445

446

\section{References}

Akaike H (1992) Information theory and an extension of the max imum likelihood principle. In Breakthroughs in statistics. Vol. 1. Edited by S. Kotz and N. Johnson. SpringerVerlag, London

Allen GA, Antons JA (1993) Sex ratio variation in the dioecious shrub Oemleria cerasiformis. Am Nat 141:537-553

Améztegui A, Brotons L, Coll L (2010) Land-use changes as major drivers of mountain pine (Pinus uncinata Ram.) expansion in the Pyrenees. Glob Ecol Biogeogr. doi: 10.1111/j.1466-8238.2010.00550.x

Bazzaz F (1997) Allocation of resources in plants: state of the science and critical questions. In: Bazzaz F, Grace J (ed) Plant resource allocation. Academic Press, San Diego, pp 137

Blanco E, Casado M, Costa M, et al. (2005) Los bosques ibéricos: Una interpretación geobotánica, 4a ed. Planeta, Barcelona

Blondel J, Aronson J (1995) Biodiversity and ecosystem function in the Mediterranean basin: human and non-human determinants. Ecol Stud 109:43-119

Borel A, Polidori JL (1983) Le Genévrier thurifère (Juniperus thurifera L.) dans le Parc National du Mercantour (Alpes-Maritimes). Bulletin de la Société Botanique de France 130, Lettres Bot. (3): 227-242

Burnham K, Anderson D (2002) Model selection and multimodel inference: a practical information-theoretic approach, 2nd ed. Springer-Verlag, New York

Canham CD, Lepage PT, Coates KD (2004) A neighborhood analysis of canopy tree competition: effects of shading versus crowding. Can J For Res 34:778-787. doi: 10.1139/X03-232

Canham CD, Uriarte M (2006) Analysis of neighborhood dynamics of forest ecosystems using likelihood methods and modeling. Ecol Appl 16:62-73

Chapin III FS, Bloom AJ, Field CB, Waring RH (1987) Plant responses to multiple environmental factors. Bioscience 37:49-57. doi: 10.2307/1310177

Cipollini ML, Whigham DF (1994) Sexual dimorphism and cost of reproduction in the dioecious shrub Lindera benzoin (Lauraceae). Am J Bot 86:585-593 


\section{Preprint submitted to Springer}

447 Coates KD, Canham CD, LePage PT (2009) Above-versus below-ground competitive effects and responses of a guild of temperate tree species. J Ecol 97:118-130. doi: 10.1111/j.1365-2745.2008.01458.x

Coomes DA, Allen RB (2007) Effects of size, competition and altitude on tree growth. J Ecol 95:1084-1097. doi: 10.1111/j.1365-2745.2007.01280.x

Crespo A, Pinillos F, Lafuente E, Broto M, Alcalde F (2006) Aprovechamiento maderero de sabina en Castilla y León: Estudio de rendimientos en la fabricación de tarima de sabina. Actas del III Coloquio Internacional sobre sabinas y enebrales Tomo II: 395403. Junta de Castilla y León, Soria, Spain

Delph LF (1990) Sex-differential resource allocation patterns in the subdioecious shrub Hebe subalpina. Ecology 71: 1342-1351

Delph L (1999) Sexual dimorphism in flowering plants. In: Geber MA, Dawson TE and Delph LF (ed) Gender and sexual dimorphism in flowering plants, Springer-Verlag, Berlin

DeSoto L, Olano JM, Rozas V, De la Cruz M (2010) Release of Juniperus thurifera woodlands from herbivore-mediated arrested succession in Spain. Appl Veg Sci 13:1525. doi: 10.1111/j.1654-109X.2009.01045.x

Doust JL, Brien GO, Doust LL (1987) Effect of density on secondary sex ratio in Silene alba (Caryophyllaceae). Am J Bot 74:40-46

Edwards M (1992) Likelihood. Johns Hopkins. University Press, Baltimore, MD, USA

Enquist BJ, Niklas KJ (2002) Global allocation rules for patterns of biomass partitioning in seed plants. Science 295:1517-1520

Freeman DC, Klikoff LG, Harper KT (1976) Differential resource utilization by the sexes of dioecious plants. Science 193:597-599

471 García-Morote FA, López-Serrano FR, Andrés M, Rubio E, González-Jimenez JL, de las Heras J (2012) Allometries, biomass stocks and biomass allocation in the thermophilic Spanish juniper woodlands of Southern Spain. For Ecol Manage 270:85-93

Gauquelin T, Bertaudière V, Montès N, Badri W, Asmode JF (1999) Endangered stands of thuriferous juniper in the western Mediterranean basin: ecological status, conservation and management. Biodiversity and Conservation 8: 1479-1498 
477 Gauquelin T, Bertaudière-Montès V, Badri W, Montès N (2002) Sex ratio and sexual dimorphism in mountain dioecious thuriferous juniper (Juniperus thurifera $\mathrm{L}$. Cupressaceae). Bot J Linn Soc 138:237-244

Gehrig-Fasel J, Guisan A, Zimmermann NE (2007) Tree line shifts in the Swiss Alps: Climate change or land abandonment? J Veg Sci 18:571-582

Gimeno TE, Camarero JJ, Granda E, et al. (2012a) Enhanced growth of Juniperus thurifera under a warmer climate is explained by a positive carbon gain under cold and drought. Tree Physiol 32:326-36. doi: 10.1093/treephys/tps011

Gimeno TE, Escudero A, Delgado A, Valladares F (2012b) Previous land use alters the effect of Climate Change and facilitation on expanding woodlands of Spanish juniper. Ecosystems 15:564-579. doi: 10.1007/s10021-012-9529-Z

Gimeno TE, Pías B, Martínez-Fernández J, et al. (2012c) The decreased competition in expanding versus mature juniper woodlands is counteracted by adverse climatic effects on growth. Eur J For Res 131:977-987. doi: 10.1007/s10342-011-0569-2

Givnish T (1988) Adaptation to sun and shade: a whole-plant perspective. Aust J Plant Physiol 15:63-92. doi: 10.1071/PP9880063

Goffe WL, Ferrier GD, Rogers J (1994) Global optimization of statistical functions with simulated annealing. J Econom 60:65-69

Gómez-Aparicio L, Canham CD (2008) Neighbourhood analyses of the allelopathic effects of the invasive tree Ailanthus altissima in temperate forests. J Ecol 96:447-458. doi: 10.1111/j.1365-2745.2007.01352.x

Gómez-Aparicio L, García-Valdés R, Ruiz-Benito P, Zavala MA (2011) Disentangling the relative importance of climate, size and competition on tree growth in Iberian forests: implications for forest management under global change. Glob Chang Biol 17:24002414. doi: 10.1111/j.1365-2486.2011.02421.x

Gower ST, McMurtrie RE, Murty D (1996) Aboveground net primary production decline with stand age: potential causes. Trends Ecol Evol 11:378-382

Hara T (1984) A stochastic model and the moment dynamics of the growth and size distribution in plant populations. J Theor Biol 109:173-190

Harper J (1977) Population biology of plants. Academic Press, London

He F, Duncan R (2000) Density-dependent effects on tree survival in al old-growth Douglas Fir Forest. J Ecol 88:676-688 


\section{Preprint submitted to Springer}

Herrera CM (1988) Plant size, spacing patterns, and host-plant selection in Osyris quadripartita, a dioecious hemiparasitic shrub. J Ecol 76:995-1006

Hilborn R, Mangel M (1997). The ecological detective: confronting models with data. Princeton University Press, Princeton, N.J.

Houle G, Duchesne M (1999) The spatial pattern of a Juniperus communis var. depressa population on a continental dune in subarctic Québec, Canada. Can J For Res 29:446450. doi: 10.1139/cjfr-29-4-446

Kobe RK (1996) Intraspecific variation in sapling mortality and growth predicts geographic variation in forest composition. Ecol Monogr 66:181-201. doi: 10.2307/2963474

Lathuillière L (1994) Le Genévrier thurifère: monographie et études des différentes stations des Alpes. Mémoire de la F.I.F.,Nancy et Conservatoire Botanique Gap-Charance

Lee WK, Gadow KV, Chung DJ, et al. (2003) DBH growth model for Pinus densiflora and Quercus variabilis mixed forests in central Korea. Ecol Mod 176:187-200

Lloyd D, Webb C (1977) Secondary sex characters in plants. Bot Rev 43:177-216

Murphy L (2012) Likelihood: Methods for maximum likelihood estimation. R package version 1.5. http://CRAN.R-project.org/package=likelihood

Lorimer CG (1983) A test of the accuracy of shade-tolerance classifications based on physiognomic and reproductive traits. Can J Bot Can Bot 61:1591-1598

Marion C, Houle G (1996) No differential consequences of reproduction according to sex in Juniperus communis var depressa (Cupressaceae). Am J Bot 83:480-488

Matesanz S, Escudero A, Valladares F (2009) Impact of three global change drivers on a Mediterranean shrub. Ecology 90:2609-2621

Mencuccini M, Martínez-Vilalta J, Hamid HA, et al. (2007) Evidence for age- and sizemediated controls of tree growth from grafting studies. Tree Physiol 27:463-473

Montesinos D. 2007. Resource availability and reproductive efficacy of the dioecious tree Juniperus thurifera. Dissertation thesis, Universitat de València, Valencia, Spain.

Montesinos D, de Luís M, Verdú M, et al. (2006) When, how and how much: genderspecific resource-use strategies in the dioecious tree Juniperus thurifera. Ann Bot 98:885-9. doi: 10.1093/aob/mcl172

Montesinos D, Villar-Salvador P, García-Fayos P, Verdú M (2012) Genders in Juniperus thurifera have different functional responses to variations in nutrient availability. New Phytol 193:705-712. doi: 10.1111/j.1469-8137.2011.03982.x 


\section{Preprint submitted to Springer}

Muller-Landau HC, Condit RS, Chave J, et al. (2006) Testing metabolic ecology theory for allometric scaling of tree size, growth and mortality in tropical forests. Ecol Lett 9:57588. doi: 10.1111/j.1461-0248.2006.00904.x

Nyland RD (1996) Silviculture: concepts and application. McGraw-Hill Series in Forest Resources. McGraw-Hill, New York

Obeso JR (2002) The costs of reproduction in plants. New Phytologist 155: 321-348

Olano JM, Rozas V, Bartolomé D, Sanz D (2008) Effects of changes in traditional management on height and radial growth patterns in a Juniperus thurifera L. woodland. For Ecol Manage 255:506-512. doi: 10.1016/j.foreco.2007.09.015

Olano JM, Zavala MA, Rozas V (2011) Disruption of Juniperus thurifera woodland structure in its northwestern geographical range: potential drivers and limiting factors. Eur J For Res 131:563-570. doi: 10.1007/s10342-011-0531-3

Ortiz PL (2002) Sex ratio and reproductive effort in the dioecious Juniperus communis subsp. alpina (Suter) Celak. (Cupressaceae) Along an Altitudinal Gradient. Ann Bot 89:205-211. doi: 10.1093/aob/mcf028

Pavón-García J (2005) Biología vegetativa y reproductiva en los primeros estadíos de crecimiento de Juniperus thurifera L. Dissertation thesis, Universidad de Alcalá de Henares, Madrid, Spain

Peterson CJ, Squiers ER (1995) Competition and succession in an aspen-white-pine forest. J Ecol 83:449-457

Poyatos R, Latron J, Llorens P (2003) Land use and land cover change after agricultural abandonment - the case of a Mediterranean mountain area (Catalan Pre-Pyrenees). Mt Res Dev 23:362-368

R Core Team (2013). R: A language and environment for statistical computing. $R$ Foundation for Statistical. Computing, Vienna, Austria. URL http://www.Rproject.org/.

Reich PB, Tjoelker MG, Machado J, Oleksyn J (2006) Universal scaling of respiratory metabolism, size and nitrogen in plants. Nature 439:457-461

Rozas V, Olano JM, De Soto L, Bartolome D (2008) Large-scale structural variation and long-term growth dynamics of Juniperus thurifera trees in a managed woodland in Soria , central Spain. Ann For Sci. doi: 10.1051/forest 


\section{Preprint submitted to Springer}

Rozas V, DeSoto L, Olano JM (2009) Sex-specific, age-dependent sensitivity of tree-ring growth to climate in the dioecious tree Juniperus thurifera. New Phytol 182:687-697. doi: 10.1111/j.1469-8137.2009.02770.x

Russo SE, Wiser SK, Coomes DA (2007) Growth-size scaling relationships of woody plant species differ from predictions of the metabolic ecology model. Ecol Lett 10:889-901. doi: 10.1111/j.1461-0248.2007.01079.x

Schulze ED (1982) Plant life forms and their carbon, water and nutrient relations. In: Springer Berlin Heidelberg (ed) Physiol. Plant Ecol. II Encycl. Plant Physiol. pp 615676

Silander Jr JA, Pacala SW (1985) Neighborhood predictors of plant performance. Oecologia 66:256-263

Silvertown J, Charlesworth D (2001) Introduction to plant population biology, 4th ed. Blackwell, London

Stokes MA, Smiley TL (1968) An introduction to tree-ring dating. University of Chicago Press, Chicago, IL

Stoll P, Newbery DM (2005) Evidence of species-specific neighborhood effects in the Dipterocarpaceae of a Bornean rain forest. Ecology 86:3048-3062

Stoll P, Weiner J, Schmid B (1994) Growth variation in a naturally established population of Pinus sylvestris. Ecology 75:660-670

Terrab A, Schönswetter P, Talavera S, et al. (2008) Range-wide phylogeography of Juniperus thurifera L., a presumptive keystone species of western Mediterranean vegetation during cold stages of the Pleistocene. Mol Phylogenet Evol 48:94-102

Thirgood J V (1981) Man and the Mediterranean Forest. A history of resource depletion. London

Thompson J (2005) Plant evolution in the Mediterranean. Oxford University Press, Oxford

Tilman D (1982) Some thoughts on resource competition and diversity inplant-communities. Ecol Stud 43:322-336

Urbieta I, Zavala M, Marañón T (2008) Human and non-human determinants of forest composition in southern Spain: evidence of shifts towards cork oak dominance due to last century management. J Biogeogr 35:1688-1700

Vasiliuskas SA, Aarssen LW (1992) Sex ratio and neighbor effects in monospecific stands of Juniperus virginiana. Ecology 73:622-632 


\section{Preprint submitted to Springer}

604

605

606

607

608

609

610

611

612

613

614

615

616

Vayreda J, Martínez-Vilalta J, Gracia M, Retana J (2012) Recent climate changes interact with stand structure and management to determine changes in tree carbon stocks in Spanish forests. Glob Chang Biol 18:1028-1041. doi: 10.1111/j.13652486.2011.02606.x

Weiner J (1984) Neighbourhood interference amongst Pinus rigida individuals. J Ecol 72:183. doi: $10.2307 / 2260012$

Zavala MA, Angulo O, Bravo de la Parra R, López-Marcos JC (2007) An analytical model of stand dynamics as a function of tree growth, mortality and recruitment: the shade tolerance-stand structure hypothesis revisited. J Theor Biol 244:440-50. doi: 10.1016/j.jtbi.2006.08.024

Zhang C, Zhao X, Gao L, Gadow KV (2009) Gender, neighboring competition and habitat effects on the stem growth in dioecious Fraxinus mandshurica trees in a northern temperate forest. Ann For Sci 66:812-812. doi: 10.1051/forest/2009068 


\section{Preprint submitted to Springer}

1 This manuscript includes 2 Figures, 4 Tables and 2 Supplementary material Figures.

2

3 Table 1 Summary data from target trees. Number of individuals, age, growth rate, trunk

4 diameter and height for each reproductive class are shown Statistical differences between

5 reproductive classess were tested using one way anova test in: Age, Growth rate*, Trunk

6 diameter**, Height. SE means standard error.

7

8 Table 2 Summary data of neighbourhood conditions for target trees in each reproductive

9 class. Range, mean and standard error (SE) are shown for each variable. NCI (Neighborhood

10 Competition Index) is the total basal area $\left(\mathrm{cm}^{2}\right)$ from neighbours contained in

11 circumferences at different distances $(1,2$ and $3 \mathrm{~m})$ from the target tree; and Aver. $\mathrm{n}^{\mathrm{o}}$ ind. is

12 the average number of individuals contained in circumferences at different distances from the target tree. Differences between reproductive classes were tested using one way anova test in NCI and with genelarize linear models (family= Poission distribution) in Aver. $\mathrm{n}^{\mathrm{o}}$ ind.

Table 3 Comparison of alternate growth models analysing the effect of size and competition at three different distances for the whole population together and for each reproductive class of the target trees. The most parsimonious model (indicated in bold) is the one with the lowest $\mathrm{AIC}_{\mathrm{c}}$. Slope and $\mathrm{R}^{2}$ (the goodness of fit) are given for the best model.

Table 4 Maximum likelihood parameter values with two unit support intervals (in

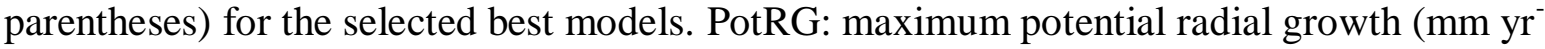

$\left.23{ }^{1}\right) ; \mathrm{X}_{0}$ : trunk diameter $(\mathrm{mm})$ of the target tree at which PotRG occurs; $\mathrm{X}_{\mathrm{b}}$ : breadth of the function; sd: standard deviation. 


\section{Preprint submitted to Springer}

1 Fig. 1 Observed frequency distribution of trunk diameter (stem diameter at $10 \mathrm{~cm}$ from the

2 ground) for male, female and non- reproductive Juniperus thurifera individuals. Diameters

3 are separated into $10 \mathrm{~mm}$ classes.

4

5 Fig. 2 Predicted radial growth $\left(\mathrm{mm} \mathrm{yr}^{-1}\right)$ as a function of size (trunk diameter in $\mathrm{mm}$ ) for 6 each reproductive class in the absence of competition effects. See Table 4 for the estimated

7 parameters of the fitted eqn 1 . Confident intervals are represented by continuous lines.

8

9 Fig. S1 Geographic distribution of Juniperus thurifera, indicating those areas where the 10 species appears as dominant. This map has been drawn based on information from the Mapa

11 Forestal de España 1:50,000 (Ministerio de Medio Ambiente and Banco de Datos de la 12 Biodiversidad).

14 Fig. S2 On the left panel, predicted vs observed growth data and the $\mathrm{R}^{2}$ (percentage of 15 variance explained of the best models). The solid lines represent linear regressions with a 16 zero intercept and slope of one. On the right panel, residuals vs predicted data for the 17 different reproductive classes and the whole dataset. 
1 Table 1 Summary data from target trees. Number of individuals, age, growth rate, trunk

2 diameter and height for each reproductive class are shown. Statistical differences between

3 reproductive classess were tested using one way anova test in: Age, Growth rate*, Trunk

4 diameter**, Height. SE means standard error.

\begin{tabular}{|c|c|c|c|c|}
\hline & & Male trees & Female trees & Non-reproductive trees \\
\hline Number of individuals & & 115 & 105 & 79 \\
\hline \multirow[t]{3}{*}{ Age (yr) } & range & $23-41$ & $26-42$ & $23-41$ \\
\hline & mean & $33.14 \mathrm{a}$ & $34.19 \mathrm{a}$ & $31.27 \mathrm{~b}$ \\
\hline & SE & 0.33 & 0.35 & 0.4 \\
\hline \multirow[t]{3}{*}{ Growth rate $\left(\mathrm{mm} \mathrm{yr}^{-1}\right)$} & range & $0.17-1.85$ & $0.26-2.78$ & $0.22-1.43$ \\
\hline & mean & $0.77 \mathrm{a}$ & $0.84 \mathrm{a}$ & $0.50 \mathrm{~b}$ \\
\hline & SE & 0.05 & 0.05 & 0.04 \\
\hline \multirow[t]{3}{*}{ Trunk diameter (mm) } & range & $28.97-165.50$ & $31.19-176.70$ & $25.46-84.35$ \\
\hline & mean & $71.86 \mathrm{a}$ & $81.04 \mathrm{a}$ & $45.02 \mathrm{~b}$ \\
\hline & SE & 3.37 & 3.43 & 2.59 \\
\hline \multirow[t]{3}{*}{ Height $(\mathrm{cm})$} & range & $150.00-470.00$ & $150.00-480.00$ & $70.00-260.00$ \\
\hline & mean & $258.17 \mathrm{a}$ & $275.52 \mathrm{a}$ & $156.89 \mathrm{~b}$ \\
\hline & SE & 8.94 & 9.11 & 6.88 \\
\hline
\end{tabular}

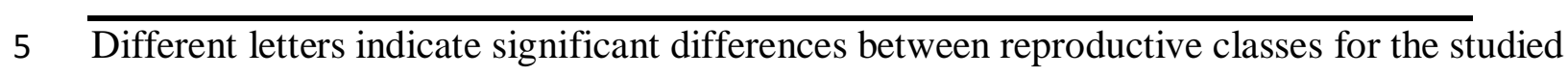

6 variables at $\alpha=0.05$.

$7 *$ Estimated at $10 \mathrm{~cm}$ from the ground

$8 * *$ Measured at $10 \mathrm{~cm}$ from the ground

9 
1 Table 2 Summary data of neighbourhood conditions for target trees in each reproductive 2 class. Range, mean and standard error (SE) are shown for each variable. NCI (Neighborhood 3 Competition Index) is the total basal area $\left(\mathrm{cm}^{2}\right)$ from neighbours contained in 4 circumferences at different distances $(1,2$ and $3 \mathrm{~m})$ from the target tree; and Aver. $\mathrm{n}^{\circ}$ ind. is 5 the average number of individuals contained in circumferences at different distances from 6 the target tree. Differences between reproductive classess were tested using one way anova 7 test in NCI and with genelarize linear models (family= Poission distribution) in Aver. $\mathrm{n}^{\circ}$ ind. 8

\begin{tabular}{|c|c|c|c|c|}
\hline & & Male trees & Female trees & Non-reproductive trees \\
\hline \multirow[t]{3}{*}{ NCI $(1 \mathrm{~m})\left(\mathrm{cm}^{2}\right)$} & range & $0-281.62$ & $0-266.00$ & $0-358.10$ \\
\hline & mean & $52.44 \mathrm{a}$ & $47.47 \mathrm{a}$ & $57.35 \mathrm{a}$ \\
\hline & SE & 6.34 & 8.24 & 8.39 \\
\hline \multirow[t]{3}{*}{$\mathrm{NCI}(2 \mathrm{~m})\left(\mathrm{cm}^{2}\right)$} & range & $32.56-644.04$ & $6.44-504.34$ & $47.80-1045.13$ \\
\hline & mean & $164.65 \mathrm{a}$ & $172.87 \mathrm{a}$ & $203.58 \mathrm{a}$ \\
\hline & SE & 14.10 & 18.31 & 18.66 \\
\hline \multirow[t]{4}{*}{$\operatorname{NCI}(3 \mathrm{~m})\left(\mathrm{cm}^{2}\right)$} & range & $35.43-$ & $140.89-$ & $158.38-1495.60$ \\
\hline & & 914.65 & 1191.94 & \\
\hline & mean & $273.87 \mathrm{a}$ & $245.45 \mathrm{ab}$ & $293.64 \mathrm{~b}$ \\
\hline & SE & 19.62 & 25.48 & 25.97 \\
\hline \multirow[t]{3}{*}{ Aver. $\mathrm{n}^{\mathrm{o}}$ ind. $(1 \mathrm{~m})$} & range & $0-10$ & $0-10$ & $0-8$ \\
\hline & mean & $2.10 \mathrm{~b}$ & $2.33 \mathrm{a}$ & $2.71 \mathrm{a}$ \\
\hline & SE & 0.09 & 0.09 & 0.07 \\
\hline \multirow[t]{3}{*}{ Aver. $\mathrm{n}^{\circ}$ ind. $(2 \mathrm{~m})$} & range & $2-24$ & $1-19$ & $3-24$ \\
\hline & mean & $8 \mathrm{~b}$ & $9 \mathrm{c}$ & $10 \mathrm{a}$ \\
\hline & SE & 0.05 & 0.05 & 0.03 \\
\hline \multirow[t]{3}{*}{ Aver. $\mathrm{n}^{\mathrm{o}}$ ind. $(3 \mathrm{~m})$} & range & $4-36$ & $7-38$ & $8-37$ \\
\hline & mean & $18 \mathrm{~b}$ & $19 \mathrm{c}$ & $20 \mathrm{a}$ \\
\hline & SE & 0.03 & 0.03 & \\
\hline
\end{tabular}




\section{Preprint submitted to Springer}

1 Different letters indicate significant differences between reproductive classes for the studied

2 variables at $\alpha=0.05$

3 
4 Table 3 Comparison of alternate growth models analysing the effect of size and 5 competition at three different distances for the whole population together and for each 6 reproductive class of the target trees. The most parsimonious model (indicated in bold) 7 is the one with the lowest $\mathrm{AIC}_{\mathrm{c}}$. NP means the number of parameters of the model. 8 Slope and $\mathrm{R}^{2}$ (the goodness of fit) is given for the best model.

9

\begin{tabular}{|c|c|c|c|c|c|c|}
\hline & & $\mathbf{N P}$ & $\mathrm{AIC}_{\mathrm{c}}$ & $\Delta \mathbf{A I C}$ & Slope: & $\mathbf{R}^{2}$ \\
\hline \multirow[t]{9}{*}{ All target trees } & Null & 2 & 219.36 & 198.12 & & \\
\hline & Size & 4 & 21.25 & 0.00 & 1.00 & 0.49 \\
\hline & Competition ( $\mathrm{R}=1 \mathrm{~m})$ & 4 & 223.34 & 202.09 & & \\
\hline & Competition $(\mathrm{R}=2 \mathrm{~m})$ & 4 & 216.18 & 194.93 & & \\
\hline & Competition $(\mathrm{R}=3 \mathrm{~m})$ & 4 & 221.46 & 200.21 & & \\
\hline & Gender competition $(\mathrm{R}=1 \mathrm{~m})$ & 10 & 223.40 & 202.15 & & \\
\hline & Gender competition $(\mathrm{R}=2 \mathrm{~m})$ & 10 & 228.32 & 207.07 & & \\
\hline & Gender competition $(\mathrm{R}=3 \mathrm{~m})$ & 10 & 228.59 & 207.34 & & \\
\hline & Size + competition $(\mathrm{R}=2 \mathrm{~m})$ & 6 & 25.28 & 4.03 & & \\
\hline \multirow[t]{8}{*}{ Male trees } & Null & 2 & 68.40 & 61.47 & & \\
\hline & Size & 4 & 6.93 & 0.00 & 1.00 & 0.44 \\
\hline & Competition ( $\mathrm{R}=1 \mathrm{~m})$ & 4 & 71.08 & 64.16 & & \\
\hline & Competition $(\mathrm{R}=2 \mathrm{~m})$ & 4 & 71.82 & 64.89 & & \\
\hline & Competition ( $\mathrm{R}=3 \mathrm{~m})$ & 4 & 70.40 & 63.48 & & \\
\hline & Gender competition $(\mathrm{R}=1 \mathrm{~m})$ & 10 & 81.36 & 74.43 & & \\
\hline & Gender competition $(\mathrm{R}=2 \mathrm{~m})$ & 10 & 75.55 & 68.62 & & \\
\hline & Gender competition $(\mathrm{R}=3 \mathrm{~m})$ & 10 & 76.72 & 69.79 & & \\
\hline \multirow[t]{4}{*}{ Female trees } & Null & 2 & 109.08 & 56.79 & & \\
\hline & Size & 4 & 52.28 & 0.00 & 1.00 & 0.35 \\
\hline & Competition $(\mathrm{R}=1 \mathrm{~m})$ & 4 & 97.53 & 45.25 & & \\
\hline & Competition $(\mathrm{R}=2 \mathrm{~m})$ & 4 & 94.98 & 42.69 & & \\
\hline
\end{tabular}




\begin{tabular}{|c|c|c|c|c|c|c|}
\hline & & $\mathbf{N P}$ & $\mathrm{AIC}_{\mathrm{c}}$ & $\Delta \mathrm{AIC}$ & Slope: $\mathbf{R}$ & \\
\hline & Competition $(\mathrm{R}=3 \mathrm{~m})$ & 4 & 97.02 & 44.73 & & \\
\hline & Gender competition $(\mathrm{R}=1 \mathrm{~m})$ & 10 & 109.94 & 57.66 & & \\
\hline & Gender competition $(\mathrm{R}=2 \mathrm{~m})$ & 10 & 96.26 & 43.97 & & \\
\hline & Gender competition $(\mathrm{R}=3 \mathrm{~m})$ & 10 & 105.07 & 52.78 & & \\
\hline & Size + competition $(\mathrm{R}=1 \mathrm{~m})$ & 6 & 56.95 & 4.66 & & \\
\hline & Size + competition $(\mathrm{R}=2 \mathrm{~m})$ & 6 & 57.00 & 4.71 & & \\
\hline & Size + competition $(R=3 m)$ & 6 & 57.02 & 4.73 & & \\
\hline & Size + gender competition $(\mathrm{R}=1 \mathrm{~m})$ & 10 & 381.08 & 328.80 & & \\
\hline & Size + gender competition $(\mathrm{R}=2 \mathrm{~m})$ & 10 & 380.43 & 328.15 & & \\
\hline & Size + gender competition $(\mathrm{R}=3 \mathrm{~m})$ & 10 & 377.65 & 325.37 & & \\
\hline $\begin{array}{r}\text { Non-reproductive } \\
\text { trees }\end{array}$ & Null & 2 & 363.19 & 46.82 & & \\
\hline & Size & 4 & 316.37 & 0.00 & 0.99 & 0.48 \\
\hline & Competition $(\mathrm{R}=1 \mathrm{~m})$ & 4 & 366.07 & 49.70 & & \\
\hline & Competition $(\mathrm{R}=2 \mathrm{~m})$ & 4 & 367.57 & 51.20 & & \\
\hline & Competition $(\mathrm{R}=3 \mathrm{~m})$ & 4 & 367.56 & 51.18 & & \\
\hline & Gender competition $(\mathrm{R}=1 \mathrm{~m})$ & 10 & 381.08 & 64.71 & & \\
\hline & Gender competition $(\mathrm{R}=2 \mathrm{~m})$ & 10 & 380.43 & 64.06 & & \\
\hline & Gender competition $(\mathrm{R}=3 \mathrm{~m})$ & 10 & 377.65 & 61.28 & & \\
\hline
\end{tabular}

10 
12 Table 4 Maximum likelihood parameter values and 2-unit support intervals [in 13 brackets] for the selected best models. Pot RG: maximum potential radial growth $\mathrm{mm}$ 14 year ${ }^{-1} ; \mathrm{X}_{0}$ : trunk diameter $(\mathrm{mm})$ of the target tree at which Pot RG occurs; $\mathrm{X}_{\mathrm{b}}$ : breadth 15 of the function; sd: standard deviation.

\begin{tabular}{|c|c|c|c|c|c|}
\hline & MODEL & Pot RG & $\mathbf{X}_{\mathbf{0}}$ & $\mathbf{X}_{\mathrm{b}}$ & sd \\
\hline \multirow[t]{2}{*}{ all trees } & Size & 2.40 & 1000 & 1.76 & 0.25 \\
\hline & & [2.33-2.47] & [960.40-1000] & [1.74-1.77] & {$[0.23-0.27]$} \\
\hline \multirow[t]{2}{*}{ Male trees } & Size & 1.93 & 616.34 & 1.61 & 0.24 \\
\hline & & [1.83-2.03] & [579.96-662.38] & [1.56-1.65] & {$[0.22-0.27]$} \\
\hline \multirow[t]{2}{*}{ Female trees } & Size & 2.56 & 996.27 & 1.69 & 0.30 \\
\hline & & [2.39-2.73] & [927.13-1000] & [1.64-1.74] & {$[0.26-0.34]$} \\
\hline \multirow[t]{3}{*}{ Non-reproductive } & & & & & \\
\hline & Size & 0.99 & 158.11 & 1.10 & 1.70 \\
\hline & & [0.94-1.00] & [146.30-169.90] & [1.05-1.17] & [1.47-2.00] \\
\hline
\end{tabular}




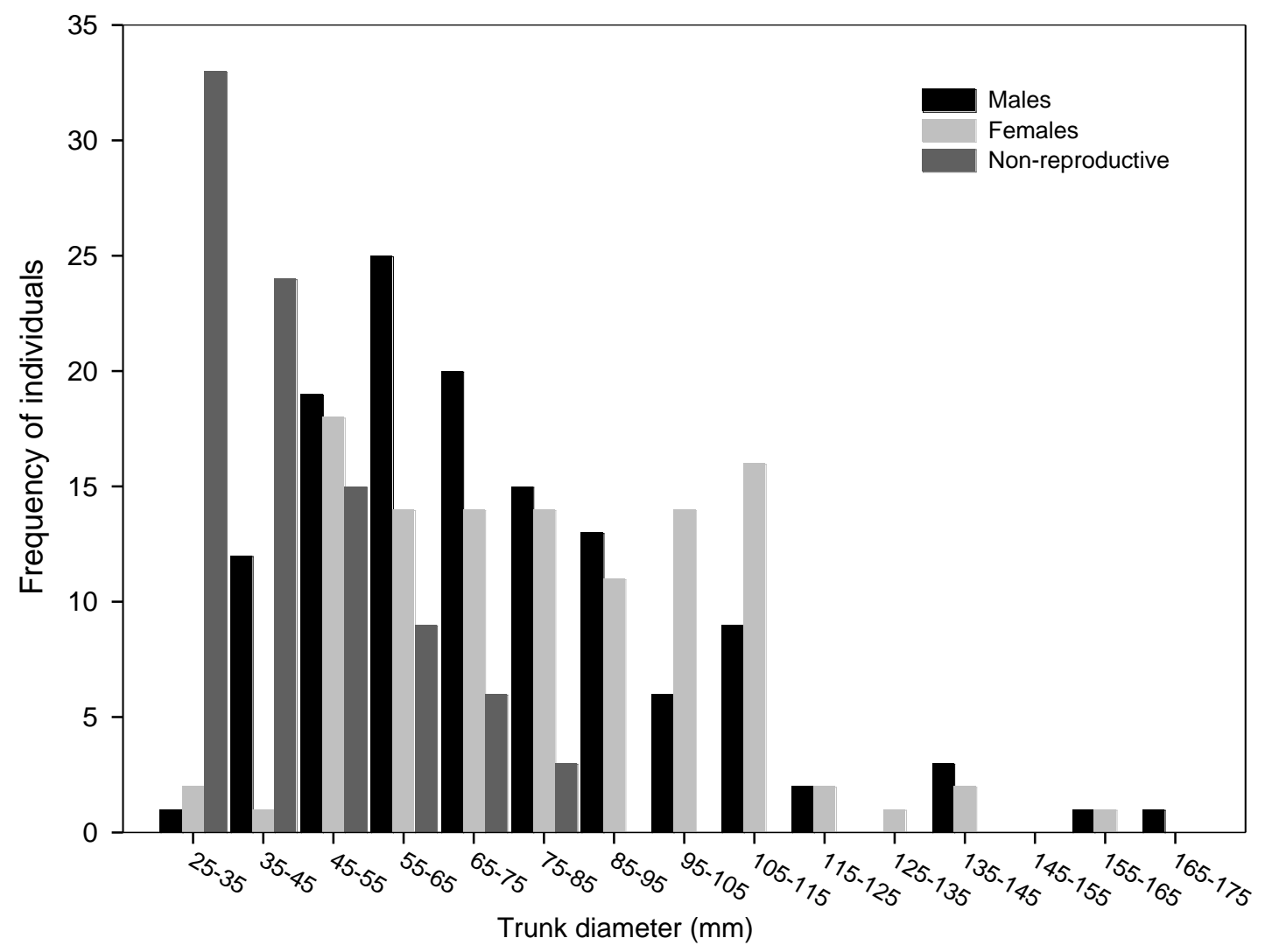

18

19 Fig. 1 Observed frequency distribution of trunk diameter (stem diameter at $10 \mathrm{~cm}$ from 20 the ground) for male, female and non- reproductive Juniperus thurifera target 21 individuals. Diameters are separated into $10 \mathrm{~mm}$ classes.

22 


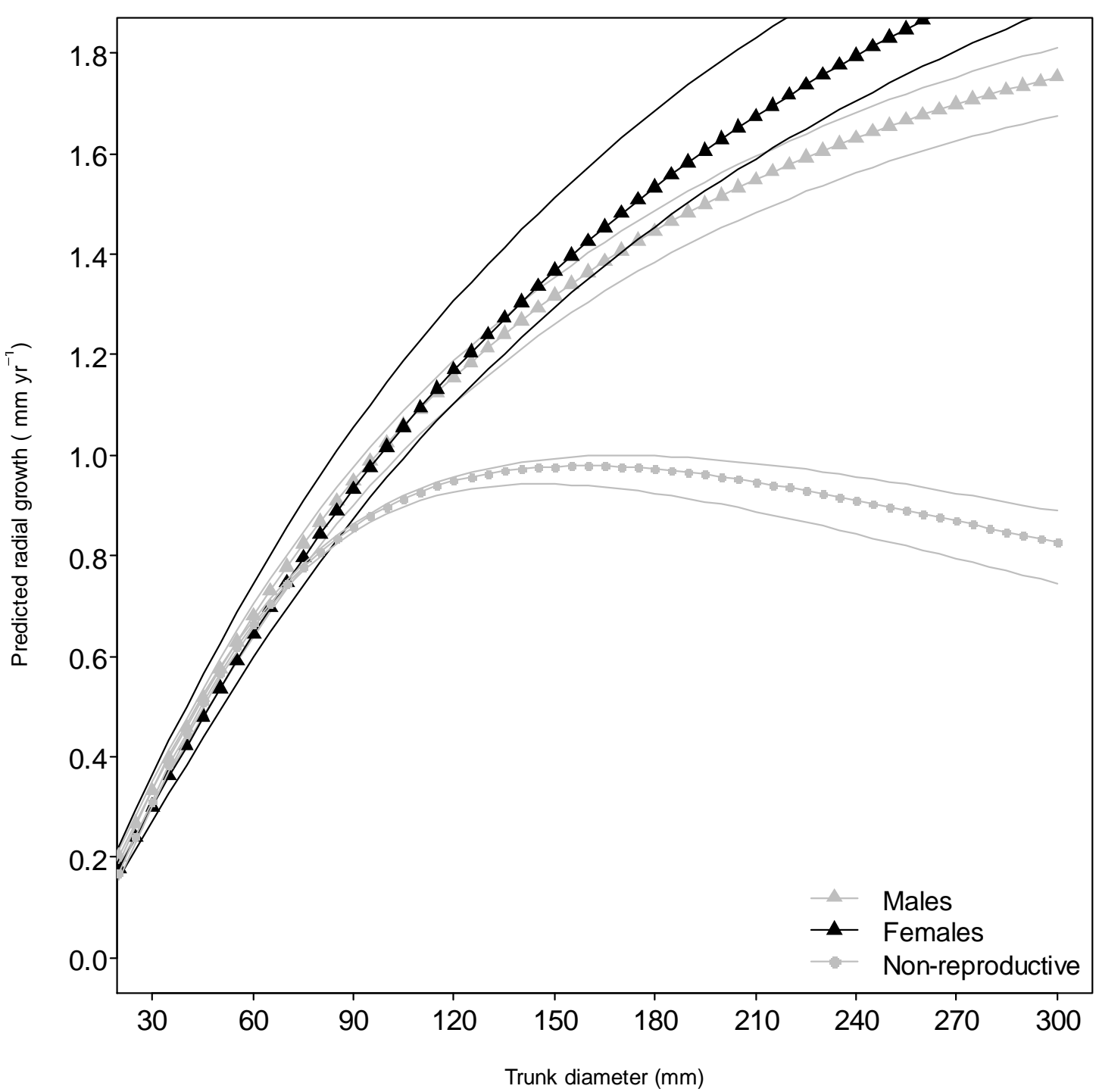

23

24 Fig. 2 Predicted radial growth $\left(\mathrm{mm} \mathrm{yr}^{-1}\right)$ as a function of size (trunk diameter in $\mathrm{mm}$ ) for 25 each reproductive class in the absence of competition effects. See Table 4 for the 26 estimated parameters of the fitted eqn 1. Confident intervals are represented by 27 continuous lines. 


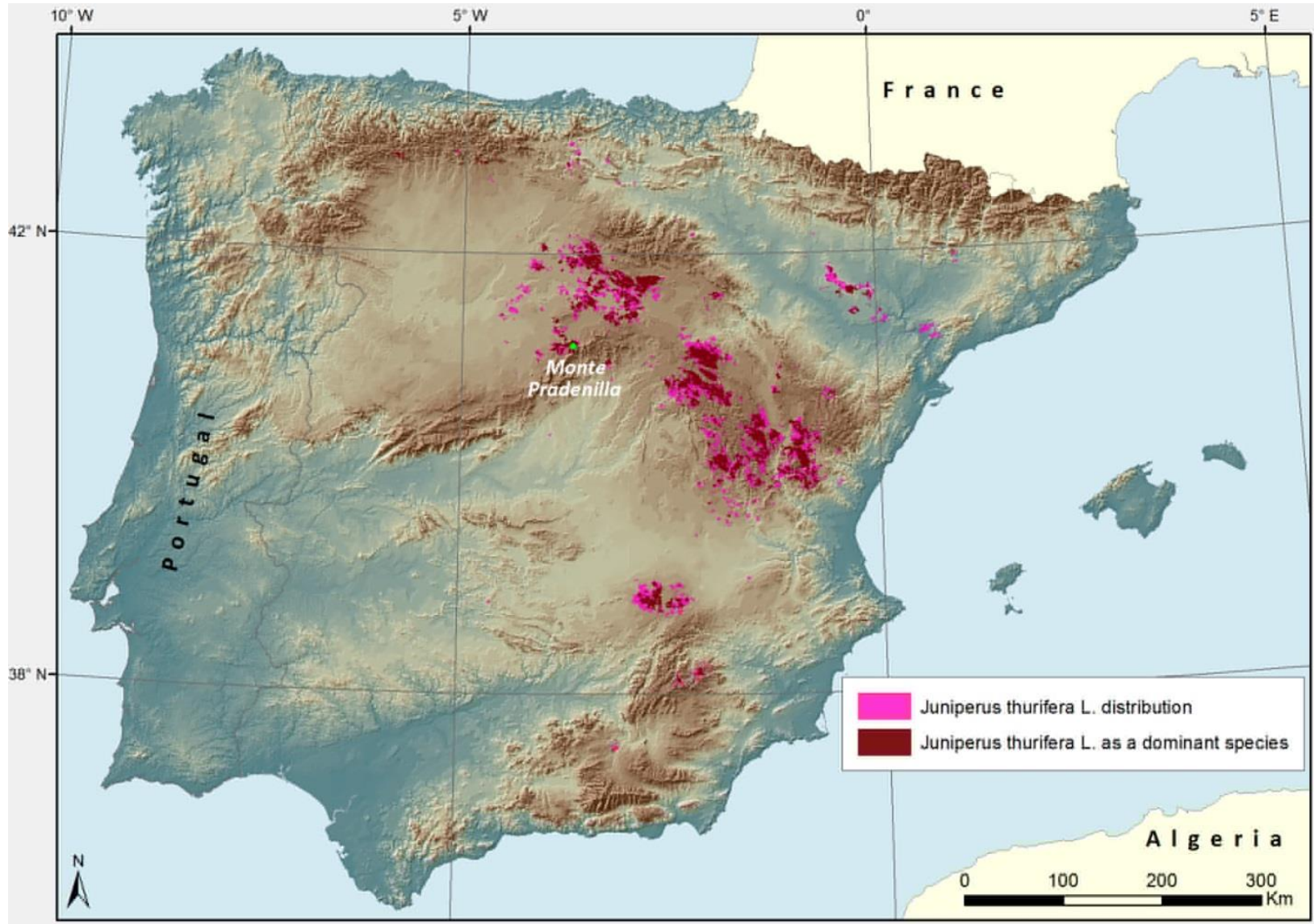

2 Fig. S1 Geographic distribution of Juniperus thurifera, indicating those areas where the species 3 appears as dominant. This map has been drawn based on information from the Mapa Forestal de 4 España 1:50,000 (Ministerio de Medio Ambiente and Banco de Datos de la Biodiversidad). 5 

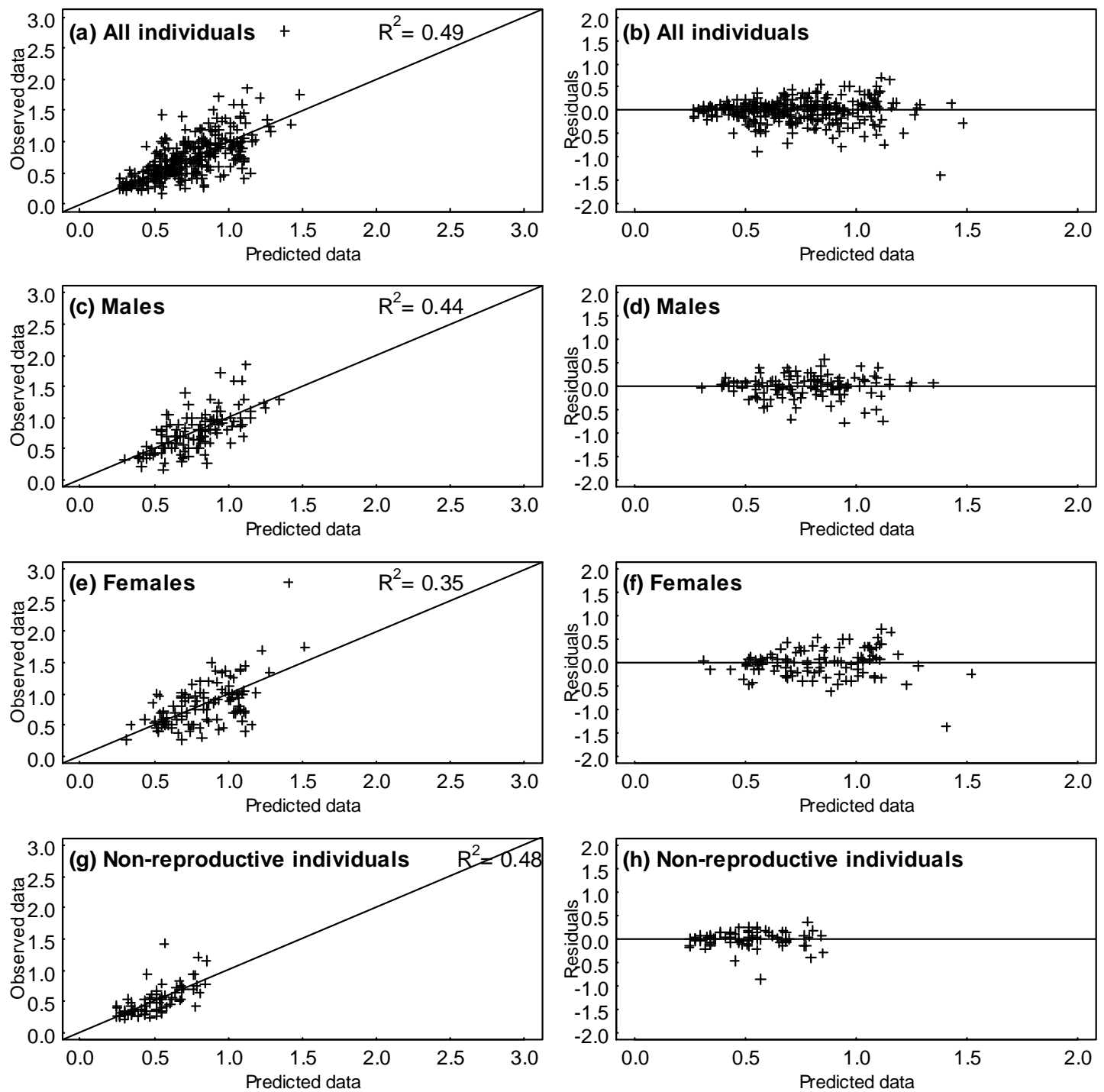

1

2 Fig. $\mathbf{S 2}$ On the left panel, predicted vs observed growth data and the $\mathrm{R}^{2}$ (percentage of

3 variance explained of the best models). The solid lines represent linear regressions with

4 a zero intercept and slope of one. On the right panel, residuals vs predicted data for the

5 different reproductive classes and the whole dataset. 